\title{
POMPEIU-LIKE THEOREMS FOR THE MEDIANS OF A SIMPLEX
}

\author{
GHada Al-AFifi, MowafFaq HajJa, Ahmad Hamdan \\ AND PANAGIOTIS T. KRASOPOULOS
}

Abstract. A theorem of Pompeiu states that the distances from the vertices of an equilateral triangle to an arbitrary point in its plane can serve as the side lengths of a triangle. A similar theorem holds for the medians of any triangle. Generalizations to higher dimensions of Pompeiu's theorem are established by M. Fiedler in 1977 and by Gh. Al-Afifi et al in a forthcoming paper. This paper is concerned with similar possible higher dimensional theorems for the medians.

Mathematics subject classification (2010): 51M04, 51M16, 51M15, 51M25, 51M20.

Keywords and phrases: Content, facet, generalized medians, simplex, isodynamic simplex, medians, Pompeiu's theorem.

\section{REFERENCES}

[1] Gh. Al-Afifi, M. HaJjA, AND A. Hamdan, Another n-dimensional generalization of Pompeiu's theorem, Amer. Math. Monthly, to appear.

[2] P. S. Bullen, A Dictionary of Inequalities, second edition, Taylor \& Francis Group, LLC, Boca Raton, Florida, 2015.

[3] M. FIEDLER, Isodynamic systems in Euclidean spaces and an n-dimensional analogue of a theorem by Ротреiu, Časopis pro pěstování matematiky 102 (1977), 370-381.

[4] L. GERBER, The orthocentric simplex as an extreme simplex, Pacific J. Math. 56 (1975), 97-111.

[5] M. HaJJA, On nested sequences of triangles, Results Math. 54 (2009), 289-299.

[6] M. HAJJA, The sequence of generalized median triangles and a new shape function, J. Geom. 96 (2009), 71-79.

[7] M. HAJJA AND M. HAYAJNEH, Impurity of the corner angles in certain special families of simplices, J. Geom. 105 (2014), 539-560.

[8] M. HajJa, M. Hayajneh, AND H. Martini, More characterizations of certain special families of simplices, Results Math. 69 (2016), 23-47.

[9] G. HEINDL, How to compute a triangle with prescribed lengths of its internal angle bisectors, Forum Geom. 16 (2016), 407-414.

[10] R. Honsberger, Mathematical Delights, The Dolciani Mathematical Expositions, no. 28, MAA, Washington, D. C., 2004.

[11] S. IzUmi, Sufficiency of simplex inequalities, Proc. Am. Math. Soc. 144 2016, 1299-1307.

[12] R. A. Johnson, Advanced Euclidean Geometry, Dover Publications, Inc., New York, 1929.

[13] P. Mironescu And L. Panaitopol, The existence of a triangle with prescribed angle bisector lengths, Amer. Math. Monthly 101 (1994), 58-60.

[14] S. F. Osinkin, On the existence of a triangle with prescribed angle bisector lengths, Forum Geom. 16 (2016), 399-405.

[15] S. Savchev and T. Andreescu, Mathematical Miniatures, Anneli Lax New Mathematical Library, No. 43, MAA, Washington, D. C., 2003. 